\title{
Preface to the special issue on energy storage and conversion
}

\author{
WANG Hai-yan(王海燕 $)^{1}$, LU Zhou-guang(卢周广 $)^{2}$ \\ 1. School of Chemistry and Chemical Engineering, Central South University, Changsha 410083, China; \\ 2. Department of Materials Science and Engineering, Southern University of Science and Technology, \\ Shenzhen 518055, China \\ (C) Central South University Press and Springer-Verlag GmbH Germany, part of Springer Nature 2019
}

Energy crisis and environmental pollution owing to the rapid consume of fossil fuel have become the two major challenges faced by human beings. Using the new energy, such as solar and wind energy to replace the fossil fuel, is a promising strategy to address the above issues. However, how to implement such new energy is still a big challenge. Developing chemical energy storage and conversion devices with high performance, low cost, long lifespan and high safety for wide applications has attracted tremendous attentions. The energy storage devices candidates include Li-ion batteries, Li-S batteries, Na-ion batteries, fuel cell, redox flow batteries and etc. In recent years, significant progresses have been made spanning from the fundamental studies to application-oriented prototypes in the field of energy storage and conversion. For this reason, we organize this special issue on "energy storage and conversion" in Journal of Central South University to show the latest advances in this field.

This special issue collects 16 contributions, including 1 review and 15 articles. The topics cover different aspects in $\mathrm{Li}$-ion batteries, Na-ion batteries, fuel cells, all-vanadium redox battery, Li-S battery and so on. Among these contributions, there are 10 papers focusing on the cathode materials (Sodium vanadate nanowire, $\mathrm{Na}_{2} \mathrm{FePO}_{4} \mathrm{~F} / \mathrm{C}, \mathrm{Li}_{2} \mathrm{FeSiO}_{4} / \mathrm{C} / \mathrm{Ag}$, anthraquinone) and anode materials $\left(\mathrm{Ce}_{2} \mathrm{Sn}_{2} \mathrm{O}_{7}\right.$ nanocubes, $\mathrm{Sb} @ \mathrm{Sb}_{2} \mathrm{O}_{3} /$ reduced graphene oxide composite, manganese oxides, spherical tremellalike $\mathrm{Sb}_{2} \mathrm{O}_{3}$, anatase $\mathrm{TiO}_{2}$ ) for $\mathrm{Li}$-ion batteries. Some emerging works on post $\mathrm{Li}$-ion batteries are also covered. A $\mathrm{Na}_{0.44} \mathrm{MnO}_{2}$ nanorods/graphene composite was synthesized by LIU Li et al as a high performance cathode material for $\mathrm{Na}$-ion batteries.
LIU Yan-yan et al reported a bio-derived N-doped porous carbon as sulfur hosts for high performance lithium sulfur batteries.

Three papers on electrochemical catalysis are also involved. In the review, ZHUANG Shu-xin reviewed the recent advances of the preparation and applications of perovskite-type oxides for electrocatalysis in oxygen/air electrodes. TANG You-gen and coworkers reported a red-blood-celllike nitrogen-doped porous carbon as a highly efficient metal-free catalyst for oxygen reduction reaction. LIU Min and coworkers developed hierarchical $\mathrm{TiO}_{2}$ nanorods with a highly active surface for photocatalytic $\mathrm{CO}_{2}$ reduction.

In addition, CHEN Yun-gui et al provided an anodic oxidation method to improve the electrochemical properties of carbon paper as negative electrode for vanadium redox battery. And LIU Fang et al proposed a SOC estimation strategy based on data driven EKF algorithm for power battery of EV and PHEV.

In summary, these contributions present the cutting-edge researches in the field of energy storage and conversion. We would like to sincerely thank all the authors for their great efforts in preparing high-quality manuscripts. We also thank the professional editorial office of Journal of Central South University for their hard-works to make this issue such a great success.

\section{Guest editors}

\section{WANG Hai-yan}

Dr. WANG Hai-yan earned his B.S (2005), M.S (2008) and Ph.D. (2012) degrees in Chemistry 
at Central South University. In 2010, he once joined Prof. Peter G Bruce's group in University of St. Andrews (UK) as a visiting Ph.D. student. Starting at 2016, he joined Prof. Minhua Shao's group at Hong Kong University of Science and Technology as a Hong Kong Scholar. Now he is an associate Professor in School of Chemistry and Chemical Engineering at Central South University. His current research interests are focused mainly on the new energy materials and devices, including aqueous/non-aqueous $\mathrm{Li}(\mathrm{Na})$ ion batteries and metal-air batteries. He has published over 90 refereed papers with him as the first or corresponding author, including Energy \& Environmental Science, Advanced Materials, Advanced Energy Materials, Nano Energy, Applied Catalysis B: Environmental, Energy Storage Materials, J. Mater Chem A (over 2750 citation times, h-index 32 , so far). He is a principal inventor of 8 Chinese patents. He is the vice director of Hunan Provincial Key Laboratory of Chemical Power Sources.

\section{LU Zhou-guang}

Dr. LU Zhou-guang is currently Professor in the Department of Materials Science and Engineering, Southern University of Science and Technology (SUSTech), China. He obtained his B.S. and M.S. from the Central South University in 2001 and 2004, respectively, and $\mathrm{PhD}$ from the City University of Hong Kong in 2009. He is the recipient of Fellow of Royal Society of Chemistry (FRSC), Fulbright Scholarship of USA Government of 2008-2009 and the Overseas High-Caliber Personnel (Level B) of Shenzhen Government in 2013. His research mainly covers the design and synthesis of nanostructures and their application in lithium/sodium ion batteries, and metal-air batteries. He has authored for more than 160 peer-review journal papers with total citations of more than 4000 and h-index of 41.

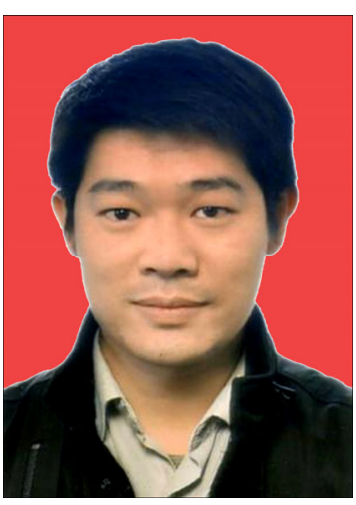

\section{WANG Hai-yan}

(PhD, Associate Professor;

Tel: +86-731-88830886;

E-mail: wanghy419@ 126.com; ORCID: 00000003-4206-0215; QQ: 52591778; Wechat: 18684957208)

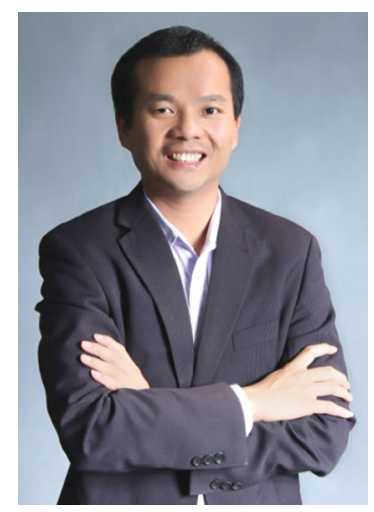

\section{LU Zhou-guang}

(PhD, Professor; Tel: +86755-88018966; E-mail: luzg@sustc.edu.cn; ORCID: 0000-0003-37699356) 